\title{
Structure and function of a novel periplasmic chitooligosaccharide-binding protein from marine Vibrio bacteria
}

Received for publication, November 18, 2017, and in revised form, February 11, 2018 Published, Papers in Press, February 14, 2018, DOI 10.1074/jbc.RA117.001012

Wipa Suginta ${ }^{\ddagger 1}$, Natchanok Sritho ${ }^{\ddagger}$, Araya Ranok $^{\S}$, David Michael Bulmer", Yoshihito Kitaoku", Bert van den Berg", and Tamo Fukamizo $\neq \|$

From the ${ }^{\ddagger}$ Biochemistry-Electrochemistry Research Unit, Institute of Science, Suranaree University of Technology, Nakhon Ratchasima 30000, Thailand, ${ }^{\S}$ Rajamangala University of Technology Isan, Nakhon Ratchasima 30000, Thailand, the "Institute for Cell and Molecular Biosciences, The Medical School, Newcastle University, Newcastle upon Tyne NE2 4HH, United Kingdom, and the "Department of Advanced Bioscience, Kindai University, Nara 631-8505 Japan

Edited by Wolfgang Peti

Periplasmic solute-binding proteins in bacteria are involved in the active transport of nutrients into the cytoplasm. In marine bacteria of the genus Vibrio, a chitooligosaccharide-binding protein $(\mathrm{CBP})$ is thought to be the major solute-binding protein controlling the rate of chitin uptake in these bacteria. However, the molecular mechanism of the CBP involvement in chitin metabolism has not been elucidated. Here, we report the structure and function of a recombinant chitooligosaccharide-binding protein from Vibrio harveyi, namely $V h C B P$, expressed in Escherichia coli. Isothermal titration calorimetry revealed that VhCBP strongly binds shorter chitooligosaccharides ((GlcNAc) ${ }_{n}$, where $n=2,3$, and 4) with affinities that are considerably greater than those for glycoside hydrolase family 18 and 19 chitinases but does not bind longer ones, including insoluble chitin polysaccharides. We also found that VhCBP comprises two domains with flexible linkers and that the domain-domain interface forms the sugar-binding cleft, which is not long extended but forms a small cavity. (GlcNAc) $)_{2}$ bound to this cavity, apparently triggering a closed conformation of $V h C B P$. Trp363 and Trp-513, which stack against the two individual GlcNAc rings, likely make a major contribution to the high affinity of $V h C B P$ for (GlcNAc) $)_{2}$. The strong chitobiose binding, followed by the conformational change of $V h C B P$, may facilitate its interaction with an active-transport system in the inner membrane of Vibrio species.

Vibrio harveyi is a Gram-negative bioluminescent marine bacterium found in tropical marine waters and is a serious pathogen of aquatic fish and invertebrates, including crusta-

This work was supported by Suranaree University of Technology and by Office of the Higher Education Commission under National Research University Project of Thailand Contract FtR.12/2558 (to W. S. and T. F.), by Thailand Research Fund and Suranaree University of Technology through Basic Research Grant BRG578001 (to W. S.), and by Suranaree University of Technology Grant SUT1-102-58-36-10 (to W. S.). The authors declare that they have no conflicts of interest with the contents of this article.

The atomic coordinates and structure factors (code 5YQW) have been deposited in the Protein Data Bank (http://wwpdb.org/).

${ }^{1}$ To whom correspondence should be addressed: Biochemistry-Electrochemistry Research Unit, School of Chemistry, Institute of Science, Suranaree University of Technology, Nakhon Ratchasima 30000, Thailand. Tel.: 66-44-226187; E-mail: wipa@sut.ac.th. cean and zooplankton (1). Chitin, a $\beta$-1,4-linked polysaccharide of GlcNAc, is an important marine biomass, which is efficiently converted by Vibrios. Thus, V. harveyi has an efficient chitin degradation system, including a chitinase A (2-5) belonging to glycoside hydrolase family 18 (GH18), ${ }^{2}$ a $\beta$ - $N$-acetylglucosaminidase $(6,7)$ belonging to the GH20 family, and a chitinoligosaccharide deacetylase $(8,9)$ belonging to carbohydrate esterase family 4 . GH18 chitinases hydrolyze $\beta$-1,4-glycosidic linkages of chitin in an endo-splitting mode, producing chitin oligosaccharides $\left(\mathrm{GlCNAc}_{n}(n=2,3,4\right.$, and more), which are further hydrolyzed into GlcNAc monomer in an exo-splitting mode by GH20 $\beta$ - $N$-acetylglucosaminidase. The carbohydrate esterase family 4 enzyme hydrolyzes the amide bond of the reducing end residue of (GlcNAc) 2 producing the deacetylated derivative (10). $V$. harveyi also has an efficient uptake system of GlcNAc or (GlcNAc) ${ }_{n}$, including an ATP-binding cassette-type (ABC) transporter for GlcNAc or (GlcNAc) 2 (11) and a chitoporin for the transport of chitin oligosaccharides (GlcNAc) ( $n=3,4,5$, and 6) (12-14). In Vibrio species, all proteins described in this study are most likely crucial for efficient degradation/uptake of chitin as nutrients.

On the other hand, it has been recognized that solute-binding proteins (SBPs) localized to the periplasmic space of Gramnegative bacteria are involved in nutrient import as components of $\mathrm{ABC}$ transporters (15). The solute binding triggers the association of SBPs with the ABC transporter located in the cytoplasmic membrane. The solute is then released from SBP and actively transported into the cytoplasm using energy provided by ATPase as one of the components of the transporter (15). In some cases, SBPs are also involved in transduction of solute signals into cytoplasm (16). Most bacterial SBPs investigated to date adopt a similar fold composed of two lobes, which are connected by one or more polypeptide chains. In the solutefree conformation, the two lobes are separated; however, the solute binds to the cleft formed between the two domains,

\footnotetext{
${ }^{2}$ The abbreviations used are: GH, glycoside hydrolase; SBP, solute-binding protein; CBP, chitooligosaccharide-binding protein; VhCBP, CBP from $V$. harveyi; VcCBP, CBP from V. cholerae; (GlcNAc) ${ }_{n}, \beta$-1,4-linked oligosaccharide of GIcNAc with a polymerization degree of $n ; A B C$, ATP-binding cassette; ITC, isothermal titration calorimetry; PDB, Protein Data Bank; RMSD, root mean square deviation.
} 


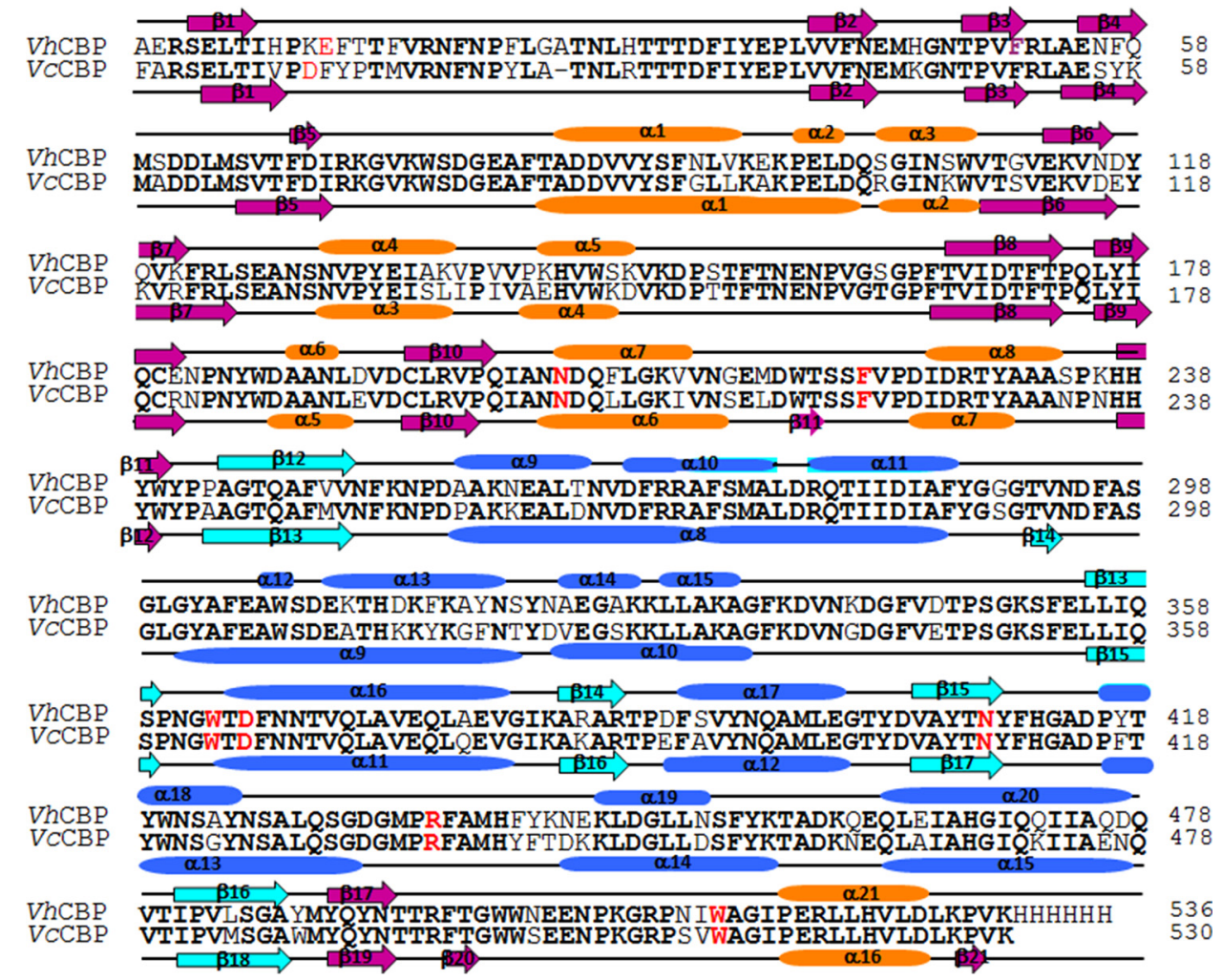

Figure 1. Amino acid sequence and secondary structure alignments of VhCBP and VcCBP. The secondary structures located in the upper domain are drawn in orange ( $\alpha$-helices) and magenta ( $\beta$-strands), whereas those located in the lower domain are drawn in blue ( $\alpha$-helices) and cyan ( $\beta$-strands). Individual secondary structures, $\alpha$-helices and $\beta$-strands, are designated as $\alpha 1-\sim \alpha 21$ and $\beta 1-\beta 21$, respectively, from the $\mathrm{N}$ terminus, and correspond to a1-a21 and b1-b21 in Fig. 4A. Amino acid residues involved in (GICNAc) ${ }_{2}$ binding in the crystal structure of $V h C B P$ in complex with (GlcNAc) ${ }_{2}$ are written in red, and are all conserved in both proteins, except Glu-10 of VhCBP. The other conserved amino acids are highlighted by bold type in the sequences. The two sequences share $83 \%$ homology.

resulting in closure of the two lobes (15). This closed conformation of SBP has been regarded as important for interaction with the transporter; hence, for the active transport of the solute (17). Similar SBPs also exists in the chitin-catabolizing system of marine Vibrio bacteria. In Vibrio cholera, an SBP has been identified to bind chitooligosacharides and thereafter referred to as $V c C B P$, following its specificity toward these specific sugars. It has been proposed that $V c C B P$ may play essential roles in controlling the rate of chitooligosaccharide transport across phospholipid membranes, as well as acting as a negative regulator of chitin catabolic sensor/kinase that controls expression of proteins involving the chitin degradation cascade (11). However, the exact physiological roles of $V c C B P$ in the chitin metabolism of Vibrios remain to be elucidated. Although crystal structures of $V c C B P$ have been registered in Protein Data Bank (PDB) under codes, 1ZTY and 1ZU0, no functional data were reported for this protein. We found a homologue of $V c C B P$ in $V$. harveyi ( $V h C B P)$, the amino acid sequence of which is highly homologous (83\%) to that of $V c C B P$, as shown in Fig. 1. Based on the amino acid sequence similarity, these two proteins do not match with any CBM family members in the CAZy database (http://www.cazy.org) ${ }^{3}$ (38) but match with the members in the SBP family 5 (InterPro no. IPR000914), which includes oligopeptide-binding proteins, murein-peptide-bind-

\footnotetext{
${ }^{3}$ Please note that the JBC is not responsible for the long-term archiving and maintenance of this site or any other third party hosted site.
}

ing proteins, and nickel-binding proteins. The binding targets of the members of this family are diverse, suggesting that the mechanism of solute binding may differ from each other despite significant sequence similarity.

We herein produced a recombinant protein of $V h C B P$, which was characterized with respect to the crystal structure and chitooligosaccharide-binding properties. The crystal structure revealed the molecular basis of the strong binding of chitooligosaccharide to VhCBP followed by the drastic conformational change, which may be important for the active transport.

\section{Results}

\section{Production of recombinant VhCBP protein by Escherichia coli expression system}

Using E. coli strain Origami (DE3) and the pET23a expression plasmid, we successfully produced the recombinant $V h C B P$ protein, which was then purified by $\mathrm{Ni}^{2+}$-affinity chro matography followed by anion exchange chromatography (HiTrap Q) and gel filtration on 16/60 Superdex 200. The profile of the final step of purification is shown in Fig. $2 \mathrm{~A}$. SDS-PAGE of the purified $V h C B P$ revealed a single protein band at $61 \mathrm{kDa}$ of molecular mass, which correspond to the calculated molecular mass of $V h C B P(61223.41 \mathrm{Da})$. From 1 liter of culture medium, we obtained $10 \mathrm{mg}$ of the purified VhCBP on average. 

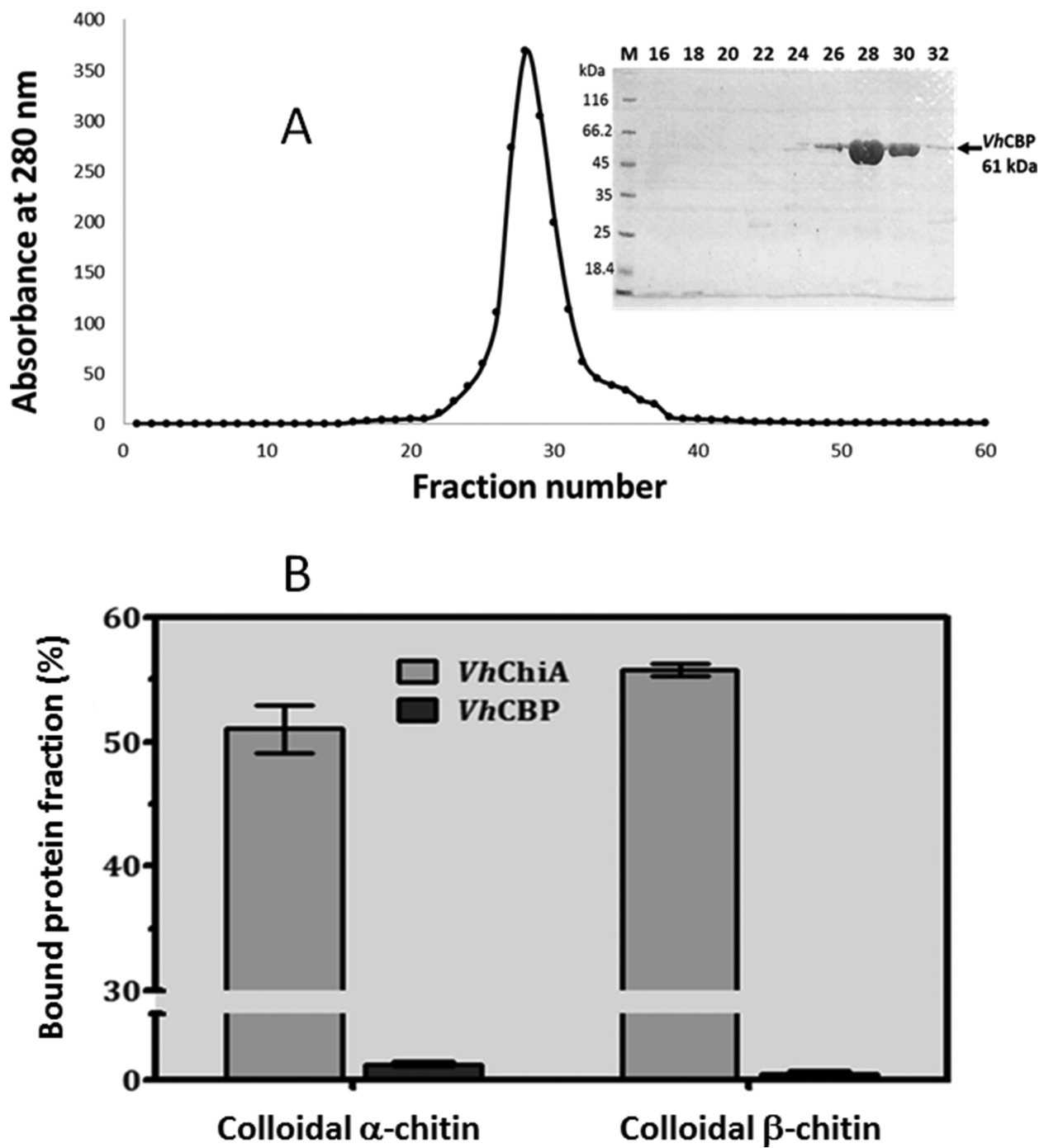

Figure 2. A, gel filtration of $\mathrm{VhCBP}$ using a column of 16/60 Superdex 200. Elution was conducted using $20 \mathrm{~mm}$ Tris- $\mathrm{HCl}$ buffer, $\mathrm{pH} 8.0$, containing $150 \mathrm{~mm}$ NaCl. Individual protein fractions were analyzed by SDS-PAGE (inset), which was performed according to the method of Laemmli (28). The gel was stained with Coomassie Brilliant Blue. B, binding abilities of $V h C B P$ toward colloidal $\alpha$-chitin and $\beta$-chitin. A mixture solution (500 $\mu$ l) comprising $5 \mu \mathrm{g}$ of protein, $1.0 \mathrm{mg}$ of colloidal chitin, and $20 \mathrm{~mm}$ Tris-HCl buffer, $\mathrm{pH} 8.0$, containing $150 \mathrm{~mm} \mathrm{NaCl}$ was incubated for $30 \mathrm{~min}$ at $4{ }^{\circ} \mathrm{C}$, and the bound protein fraction was calculated from the protein content of the supernatant determined by the method of Bradford (30). A chitinase A from V. harveyi (18) was used as a positive control.

Because prediction of post-translational glycosylation suggested two putative $\mathrm{N}$-glycosylation sites (amino acids $367-$ 369, Asn-Asn-Thr and amino acids 493-495, Asn-Thr-Thr) for $V h C B P$, we carried out digestion of the protein by $N$-glycosidase $\mathrm{F}$ to prove the glycosylation status of $V h \mathrm{CBP}$. The results showed no difference in the migration of $V h C B P$ on SDS-PAGE gel before and after the enzyme digestion, indicating that $V h C B P$ is not $N$-glycosylated (data not shown).

\section{Chitooligosaccharide binding to VhCBP}

Before testing soluble sugars, GlcNAc to (GlcNAc) $)_{6}$, we conducted the binding experiments using insoluble chitin. As shown in Fig. 2B, the relative amounts of bound proteins were much lower in $V h C B P$ than in chitinase A from $V$. harveyi $(V h C h i A)$, which was reported to have a strong affinity to both colloidal $\alpha$ - and $\beta$-chitins (18), as a positive control. VhChiA was bound to both the colloidal $\alpha$ - and $\beta$-chitins by $50-55 \%$ of the total protein content, whereas the amounts of bound fractions for VhCBP were less than 1\%. VhCBP did not exhibit a significant ability of insoluble chitin binding. Then we tested soluble sugars from GlcNAc to (GlcNAc) ${ }_{6}$ for its binding ability to $V h$ CBP using isothermal titration calorimetry (ITC). The thermograms and theoretical fits for the individual titration experiments are shown in Fig. $3(A-F)$. Titration of GlcNAc (Fig. $3 A$ ) released only a background heat, indicating no significant interaction. The thermograms obtained for (GlcNAc) ${ }_{2}$, $(\mathrm{GlcNAc})_{3}$, and (GlcNAc) $)_{4}$ exhibited strong heat releases (Fig. $3, B-D)$, and their binding isotherms suggested high affinities to VhCBP. The thermodynamic parameters obtained from data fitting are listed in Table 1. The stoichiometries for (GlcNAc) ${ }_{2}$, $(\text { GlcNAc })_{3}$, and (GlcNAc) $)_{4}$ were from 0.7 to 0.8 , suggesting a simple 1:1 binding mechanism. The binding affinities were almost identical to each other $\left(\Delta G^{\circ}=-38\right.$ to $\left.-40 \mathrm{~kJ} / \mathrm{mol}\right)$. The favorable enthalpy changes $\left(\Delta H^{\circ}\right)$ for (GlcNAc) $)_{3}$ and (GlcNAc) ${ }_{4}$ $(-41.8$ and $-44.4 \mathrm{~kJ} / \mathrm{mol})$ were much lower than that of $(\text { GlcNAc })_{2}(-91.6 \mathrm{~kJ} / \mathrm{mol})$, and the lower enthalpy changes were compensated by the decrease in unfavorable entropy changes (from 51.8 to 3.0 and $6.3 \mathrm{~kJ} / \mathrm{mol}$ of $-T \Delta S^{\circ}$ ), resulting in 

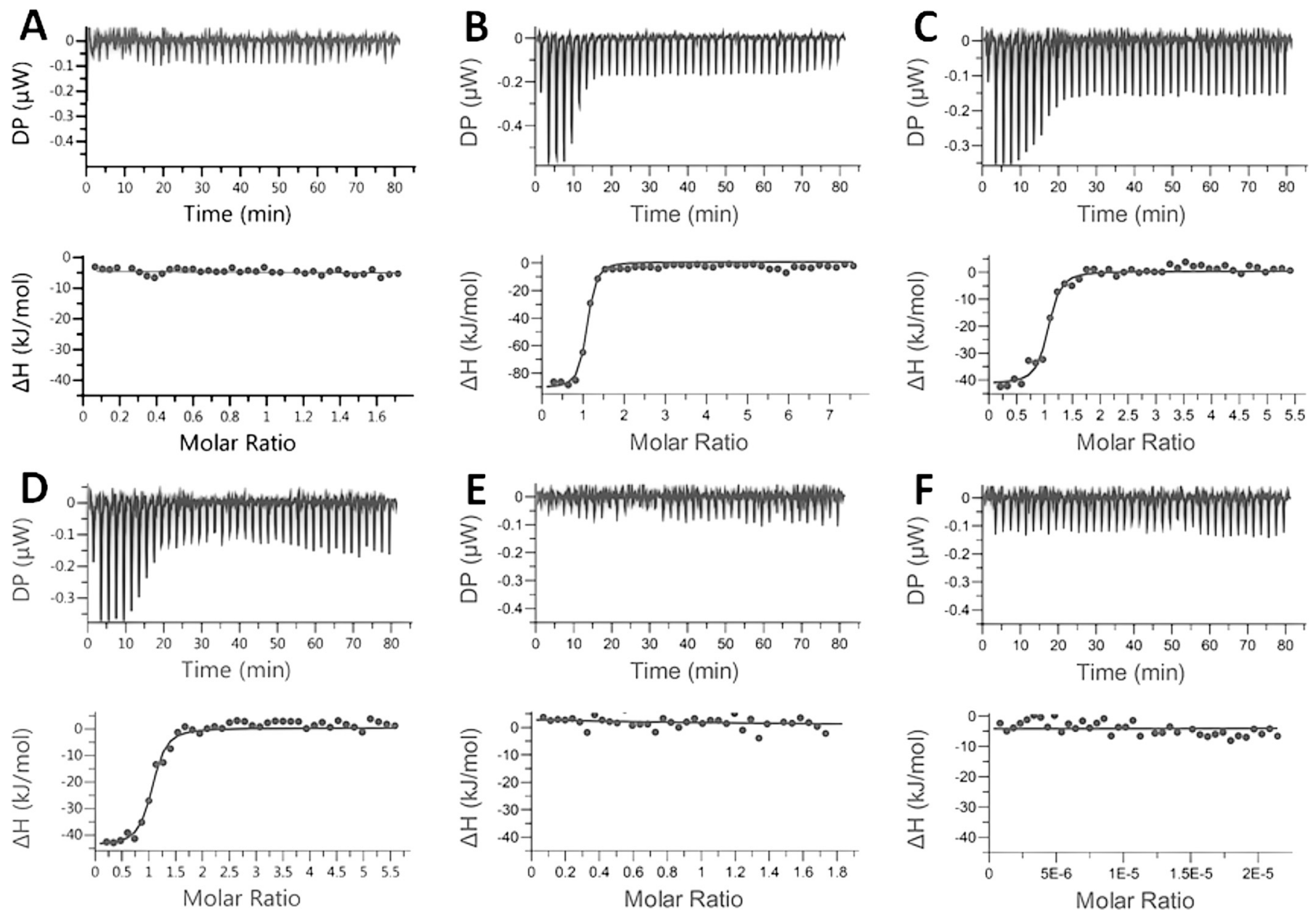

Figure 3. ITC thermograms (upper panels) and binding isotherms with theoretical fits (lower panels) obtained for the binding of GIcNAc ( $A$ ), (GIcNAC)

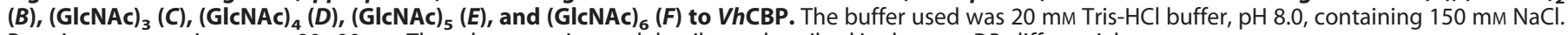
Protein concentrations were $80-90 \mu \mathrm{m}$. The other experimental details are described in the text. $D P$, differential power.

Table 1

Thermodynamic parameter for ligand binding to VhCBP determined by ITC

The equilibrium dissociation constants $\left(K_{d}\right)$ were obtained from the thermograms shown in Fig. $3(B-D)$. The values represent means \pm S.D. from three independent sets of the experiments.

\begin{tabular}{clcccl}
\hline Ligands & $\boldsymbol{n}$ (stoichiometry) & $\boldsymbol{K}_{\boldsymbol{d}}$ & $\boldsymbol{\Delta} \boldsymbol{H}^{\circ}$ & $\boldsymbol{\Delta} \boldsymbol{G}^{\circ}$ & $-\boldsymbol{T} \boldsymbol{\Delta} \boldsymbol{S}^{\circ}$ \\
\hline & & $n M$ & $\mathrm{~kJ} / \mathrm{mol}$ & $\mathrm{kJ} / \mathrm{mol}$ & $\mathrm{kJ} / \mathrm{mol}$ \\
(GlcNAc) $_{2}$ & 0.7 & $31 \pm 8.3$ & -91.6 & -39.8 & 51.8 \\
(GlcNAc) $_{3}$ & 0.8 & $48 \pm 10.3$ & -41.8 & -38.8 & 3.0 \\
(GlcNAc $_{4}$ & 0.7 & $66 \pm 17.9$ & -44.4 & -38.1 & 6.3 \\
\hline
\end{tabular}

similar affinities of (GlcNAc) $)_{2-4} \cdot(\text { GlcNAc })_{5}$ and $(\text { GlcNAc })_{6}$ also released no significant heat, underlying no binding affinity of $V h C B P$ toward longer-chain chitooligosaccharides. The ITC results suggested that two units of GlcNAc are necessary and sufficient for interaction with $V h C B P$.

\section{Crystal structure of VhCBP in complex with (GICNAC)}

We successfully solved the crystal structure of VhCBP in complex with (GlcNAc) ${ }_{2}$ at $1.4 \AA$ resolution but failed to produce X-ray-diffraction quality crystals of the unliganded $V h C B P$. The crystallographic and refinement statistics are listed in Table 2. Fig. $4 A$ shows the overall structure of $V h C B P$ in complex with (GlcNAc) $)_{2}$, which adopts a two-domain conformation. The individual domains are designated as the upper domain (colored in magenta) and the lower domain (colored in cyan) in this report. (GlcNAc) ${ }_{2}$ (colored in wine red) was observed in the very narrow cleft between the two domains. In the upper domain (Fig. 1; amino acids 1-241, $\alpha 1-\alpha 8$, and $\beta 1-\beta 11$; amino acids $488-530, \alpha 21$, and $\beta 17$ ), a cluster of several $\alpha$-helices and loop structures is supported from both sides by two major antiparallel $\beta$-sheets $(\beta 1-\beta 8-\beta 9-\beta 10$ and $\beta 4-\beta 5$ $\beta 6-\beta 7)$ and two minor antiparallel $\beta$-sheets $(\beta 2-\beta 3$ and $\beta 11$ $\beta 17)$, forming a hat-like fold, which is decorated by two-additional $\alpha$-helices ( $\alpha 7$ and $\alpha 8$ ). The electron density of the $\mathrm{C}$-terminal hexahistidine residues was not observed in this structure. In the lower domain (Fig. 1; amino acids 242-487, $\alpha 9-\alpha 20, \beta 12-\beta 16)$, a three-stranded antiparallel $\beta$-sheet ( $\beta 12$ $\beta 15-\beta 16)$ and a two-stranded parallel $\beta$-sheet $(\beta 13-\beta 14)$ are surrounded by $12 \alpha$-helices. A metal ion (colored in orange) was observed in the central part of the lower domain as shown in Fig. $4 . A$. This was successfully modeled as $\mathrm{Ni}^{2+}$, but not as $\mathrm{Mg}^{2+}$ or $\mathrm{Mn}^{2+}$ as found in the crystal structure of $V c C B P$ (PDB code 1ZU0). The residual $\mathrm{Ni}^{2+}$ was likely present during the $V h C B P$ preparation using $\mathrm{Ni}^{2+}$-agarose affinity chromatography (see "Experimental Procedures"). Two flexible linkers (colored in blue) located between $\beta 11$ and $\beta 12$ (Tyr-241, Pro-242, and Pro243 ) and between $\beta 16$ and $\beta 17$ (Tyr-488 and Met-489) connect the two domains as a hinge that forms the sugar-binding cleft, 
Table 2

Data collection and refinement statistics

Statistics for the highest-resolution shell are shown in parentheses.

\begin{tabular}{|c|c|}
\hline Beamline & I04-1 \\
\hline Wavelength & 0.92819 \\
\hline Resolution range $(\AA)$ & $46.80-1.36(1.40-1.36)$ \\
\hline Space group & P 3121 \\
\hline Unit cell & $\begin{array}{l}54.6854 .68306 .4590 .00 \\
\quad 90.00120 .00\end{array}$ \\
\hline Total reflections & $1105833(55875)$ \\
\hline Unique reflections & $115984(8241)$ \\
\hline Multiplicity & $9.5(6.8)$ \\
\hline Completeness (\%) & $99.8(97.7)$ \\
\hline Mean $I / \sigma(I)$ & $7.6(1.2)$ \\
\hline Wilson B-factor & 13.92 \\
\hline$R_{\text {merge }}$ & $0.132(1.659)$ \\
\hline$R_{\text {meas }}^{\text {merge }}$ & $0.139(1.807)$ \\
\hline$R_{\text {pim }}^{\text {meas }}$ & $0.044(0.697)$ \\
\hline $\mathrm{CC}_{1 / 2}$ & $0.995(0.067)$ \\
\hline Reflections used in refinement & 112,276 \\
\hline Reflections used for $R_{\text {free }}$ & 5458 \\
\hline$R_{\text {work }}$ & 0.1706 \\
\hline$R_{\text {free }}$ & 0.2027 \\
\hline Number of non-hydrogen atoms & 4466 \\
\hline Macromolecules & 4369 \\
\hline Ligands & 52 \\
\hline Solvent & 472 \\
\hline Protein residues & 532 \\
\hline \multicolumn{2}{|l|}{ Root-mean-square deviation (RMSD) } \\
\hline Bonds $(\AA)$ & 0.010 \\
\hline Angles $\left(^{\circ}\right)$ & 1.055 \\
\hline \multicolumn{2}{|l|}{ Ramachandran } \\
\hline Favored (\%) & 96.98 \\
\hline Allowed (\%) & 3.02 \\
\hline Outliers (\%) & 0.00 \\
\hline Rotamer outliers (\%) & 1.48 \\
\hline Clashscore & 1.84 \\
\hline Average B-factor $\left(\AA^{2}\right)$ & 21.376 \\
\hline Macromolecules & 20.477 \\
\hline Ligands & 34.056 \\
\hline Solvent & 34.532 \\
\hline $\begin{array}{l}\text { Number of translation-libration-screw } \\
\text { (TLS) groups }\end{array}$ & 10 \\
\hline
\end{tabular}

where (GlcNAc) 2 was bound. However, the bound sugar was invisible in the surface model of the structure (Fig. $5 \mathrm{~A}$ ), indicating that (GlcNAc) ${ }_{2}$ was buried inside and completely hidden by the surrounding amino acids. The complex structure of $V h C B P$ was very similar to that of the unpublished $V c C B P$ in complex with (GlcNAc) ${ }_{2}$ (PDB code 1ZU0) with an RMSD of $0.46 \AA$ (Fig. $4 B)$. On the other hand, the crystal structure of an unliganded form of $V c C B P$ was also registered in the PDB (code 1ZTY) and considerably differed from that of liganded VhCBP (RMSD = $7.05 \AA$ ), as shown in Fig. 4C. The cleft between the upper (colored in yellow) and lower (colored in brown) domains was widely opened in the unliganded form of $V c C B P$, as shown in the surface model of the structure (Fig. 5B). (GlcNAc) ${ }_{2}$ binding to the hinge region of $V h C B P$ appeared to strongly affect the protein conformation and to narrow the cleft between the two domains through a domain motion.

\section{Binding mode of (GICNAC)}

Fig. $6 A$ shows a close-up view of the (GlcNAc) $)_{2}$ binding site of $V h C B P$. Clear electron density for the two sugar units was found at the interface between the upper and lower domains. $(\mathrm{GlcNAc})_{2}$ was sandwiched between two tryptophan side chains by face-to-face stacking interactions; one is from the upper domain (Trp-513), and the other is from the lower domain (Trp-363). In addition to the stacking interactions, a number of hydrogen bonds are formed between VhCBP and the
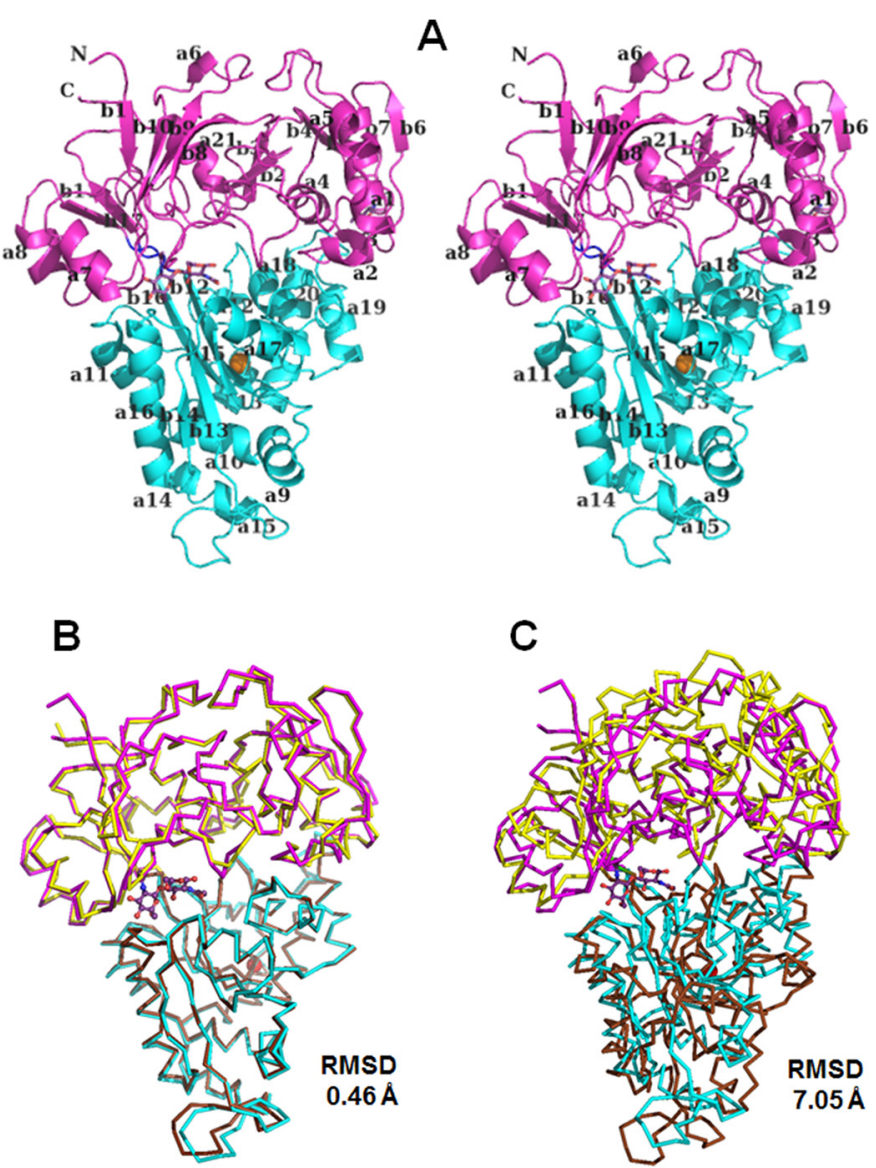

Figure 4. Crystal structure of VhCBP in complex with (GIcNAc) ${ }_{2} \cdot A$, stereo view of the main chain conformation shown by ribbon model. The upper domain is colored in magenta, whereas the lower domain is colored in cyan. Two linkers connecting the two domains (Tyr-241, Pro-242, and Pro-243; Tyr488 and Met-489) are colored in blue. Secondary structure elements are designated as a1-a21 for $\alpha$-helices and b1-b17 for $\beta$-strands, from the $N$ terminus, corresponding to $\alpha 1-\alpha 21$ and $\beta 1-\beta 17$ in Fig. 1, respectively. The bound $(\mathrm{GlcNAC})_{2}$ is represented by stick model colored in wine red. The $\mathrm{N}$ and $\mathrm{C}$ termini are indicated by $N$ and $C$, respectively. A metal ion located in the lower domain was modeled as $\mathrm{Ni}^{2+}$ and is represented by an orange sphere. $B$, superimposition of the $C \alpha$ trace of the structure of $V h C B P-(\mathrm{GlcNAC})_{2}$ complex with that of the VCCBP-(GICNAC), complex (PDB code 1ZU0), in which the upper domain is colored in yellow, whereas the lower domain is colored in brown. C, superimposition of the $\mathrm{C} \alpha$ trace of the structure of $V h C B P-(\mathrm{GlcNAC})_{2}$ complex with that of the unliganded VCCBP (PDB code 1ZTY). The color system is the same as in $B$.

bound sugar (Fig. 6B). Five direct hydrogen bonds are observed with the non-reducing end GlcNAc. The hydroxyl oxygens of C3 and C4 interact with the main chain nitrogen of Phe-222 and side chain nitrogen of Asn-204, respectively. The hydroxyl oxygen of C6 also interacts with the side chain carboxylate of Asp365 . The acetamido nitrogen and oxygen interact with the side chain carboxylate of Glu-10 and the indole nitrogen of Trp-513, respectively. On the other hand, three hydrogen bonds appeared to be directly formed with the reducing end GlcNAc. The acetamido oxygen forms a hydrogen bond with the guanidyl nitrogen of Arg-436, and the C3 hydroxyl oxygen also forms a hydrogen bond with the side chain nitrogen of Asn-409. The C6 hydroxyl oxygen interacts with the side chain oxygen of Glu-10. All interacting amino acids described here are conserved in $V c C B P$ (Fig. 1) except Glu-10. In addition to these direct hydrogen bonds, several water-mediated hydrogen 
A: $\quad$ hhCBP in complex with (GIcNAc) 2

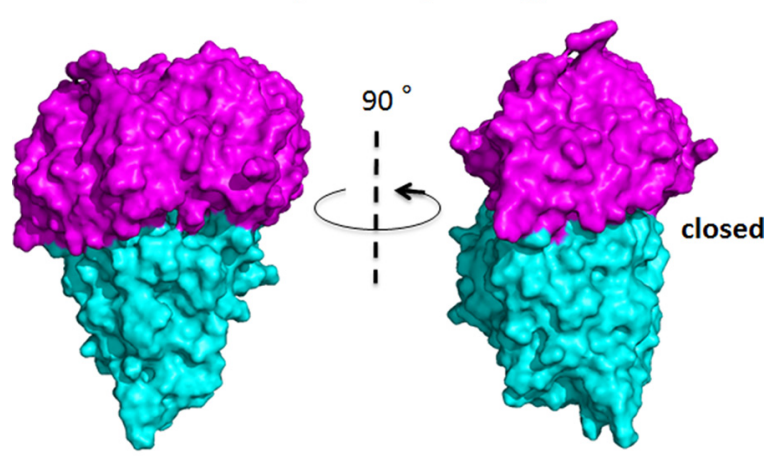

B: $\quad$ unliganded $V c C B P$

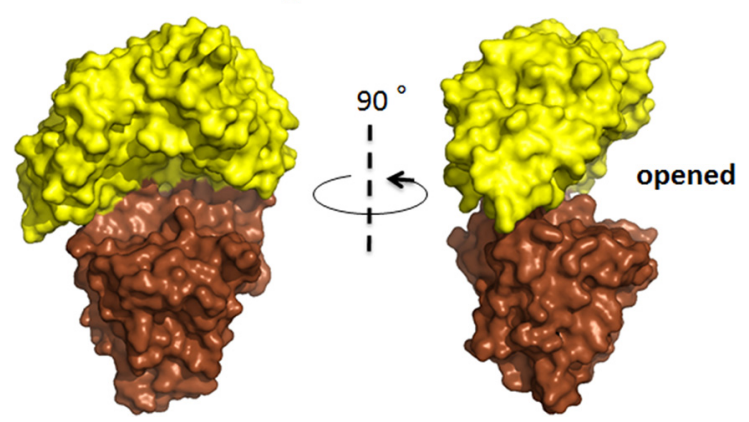

Figure 5. $A$, surface model of the structure of VhCBP in complex with (GlcNAc) $)_{2}$. The bound (GlcNAc) ${ }_{2}$ is invisible, because it is completely hidden by surrounding amino acids derived from both upper and lower domains. The color system is the same as in Fig. 4A. The binding cleft between the upper and lower domains is closed upon (GlcNAC) ${ }_{2}$ binding, as shown in the side view (right panel). $B$, surface model of the structure of unliganded VCCBP. The color system is the same as in Fig. $4 B$. The binding cleft between the upper and lower domains is opened, as shown in the side view (right panel).

bonds are also formed with the bound (GlcNAc) ${ }_{2}$, as shown in Fig. $6 B$.

\section{Discussion}

When the amino acid sequence of $V h C B P$ was analyzed by the Pfam protein families database (http://pfam.xfam.org), ${ }^{3}$ the protein was found to belong to the SBP family 5 . When the amino acid sequence of $V h C B P$ was analyzed, we found two more proteins possessing an ability to interact with $(\mathrm{GlcNAc})_{n}$. The first is periplasmic (GlcNAc) ${ }_{2}$-binding protein. This protein is thought to interact with the corresponding $\mathrm{ABC}$ transporter from Vibrio sp. JCM19052. The amino acid sequence of the protein is $99 \%$ homologous to that of $V h C B P$. The second is the chitooligosaccharide-binding protein from V.cholera $(V c C B P)$. The X-ray structure of $V c C B P$ has already been registered in the Protein Data Bank. These proteins may play important roles in the active transport of the solutes derived from chitin and the related compounds. However, most sugarbinding proteins, such as maltose- and galactose-binding proteins, are distributed to SBP families 1 and 2 (InterPro no. IPR000914), (19). Maltose-binding proteins belonging to the SBP family 1 and galactose-binding proteins belonging to the SBP family 2 are smaller in size (396-438 residues and $296-$ 306 residues, respectively) than those of $V h C B P$ and $V c C B P$ belonging to the SBP family 5 . The dissociation constants of these binding proteins toward the carbohydrates were reported to be $\sim 1.0 \mu \mathrm{M}$ (19). Nevertheless, no functional data have been reported for these chitooligosaccharide-binding proteins. We first described herein the structural and functional details of the chitooligosaccharide-binding protein from $V$. harveyi (VhCBP), which is highly homologous to that from Vibrio cholerae $(V c \mathrm{CBP})$.

Binding experiments for $V h C B P$ revealed that the protein did not bind insoluble chitin polysaccharide but bind chitooligosaccharides with the polymerization degrees from 2 to 4 (Figs. $2 B$ and 3 and Table 1) with $K_{d}$ values of 31-66 nM, 15-30 higher affinities than those of maltose- and galactose-binding proteins (19). ITC analysis of (GlcNAc) ${ }_{n}$ binding were thoroughly conducted for GH18 chitinase B from Serratia marcescens and a GH19 chitinase from Bryum coronatum (20, 21), both of which have a long-extended binding cleft for $(\mathrm{GlcNAc})_{n}$. In both cases, the longer the chain length of (GlcNAc) ${ }_{n}$, the higher the favorable free energy changes of binding $\left(\Delta G^{\circ}\right)$. The $\Delta G^{\circ}$ values of $(\mathrm{GlCNAc})_{3}$ to $(\mathrm{GlcNAc})_{6}$ were $-20,-31,-35$, and -38 $\mathrm{kJ} / \mathrm{mol}$ for the GH18 enzyme, whereas the values were -21 , $-28,-33$, and $-36 \mathrm{~kJ} / \mathrm{mol}$ for the GH19 enzyme, respectively. For $V h C B P$, however, the $\Delta G^{\circ}$ values $(-38$ to $-40 \mathrm{~kJ} / \mathrm{mol}$ ) were much higher than those of the chitinases, and were not clearly dependent on the degree of polymerization of $(\text { GlcNAc })_{n}(n=$ 2,3 , and 4). State of the (GlcNAc) ${ }_{n}$ binding site for $V h C B P$ appears to be different from those for the chitinases. As shown in Figs. 4-6, the (GlcNAc) ${ }_{2}$-binding site of $V h C B P$ is unlikely long-extended but forms a small cavity, which can accommodate only a few sugar moieties. This may be the reason why the affinity toward (GlcNAc) $)_{2}$ is somewhat higher than those toward (GlcNAc) $)_{3}$ and (GlcNAc) $)_{4}$. The third and fourth GlcNAc residues may interfere with the binding to VhCBP to some extent.

In the crystal structure of $V h C B P$ in complex with (GlcNAc) $)_{2}$, five hydrogen bonds are formed with the non-reducing end GlcNAc, whereas three bonds are formed with the reducing end GlcNAc (Fig. 6B). It appeared that the non-reducing end GlcNAc is more strongly recognized by $V h C B P$. More importantly, stacking $\mathrm{CH}-\pi$ interactions with the individual sugar residues are formed by two tryptophan residues: Trp-363 from the lower domain and Trp-513 from the upper domain, respectively (Fig. 6A). In the unliganded structure of $V c C B P$, the corresponding tryptophan residues are located apart from each other $(17.2 \AA)$. In the liganded structure of $V c C B P$ and also $V h$ CBP, the two tryptophans come close to each other (8.0 $\AA$ ), and then (GlcNAc) $)_{2}$ has been sandwiched between the two tryptophan residues, forming tight stacking interactions. This explains why $V h C B P$ has much higher affinities toward chitin oligosaccharides as compared with GH18 and GH19 chitinases. As seen from the sequence alignment shown in Fig. 1, most amino acids interacting with (GlcNAc) ${ }_{2}$ are conserved between $V h C B P$ and $V c C B P$, except Glu-10/Asp-9, which is only a conservative mutation. The binding affinity of $V c C B P$ toward (GlcNAc) $)_{2}$ is most likely strong as in the case of $V h C B P$.

Although $\mathrm{Ni}^{2+}$ ion was found at the central part of the lower domain, it was far from the (GlcNAc) $)_{2}$-binding site. It is unlikely that the $\mathrm{Ni}^{2+}$ ion is directly involved in the (GlcNAc) binding. In the crystal structure of $V c C B P, \mathrm{Mg}^{2+}$ or $\mathrm{Mn}^{2+}$ is located in the lower domain; however, the metal-binding site is 

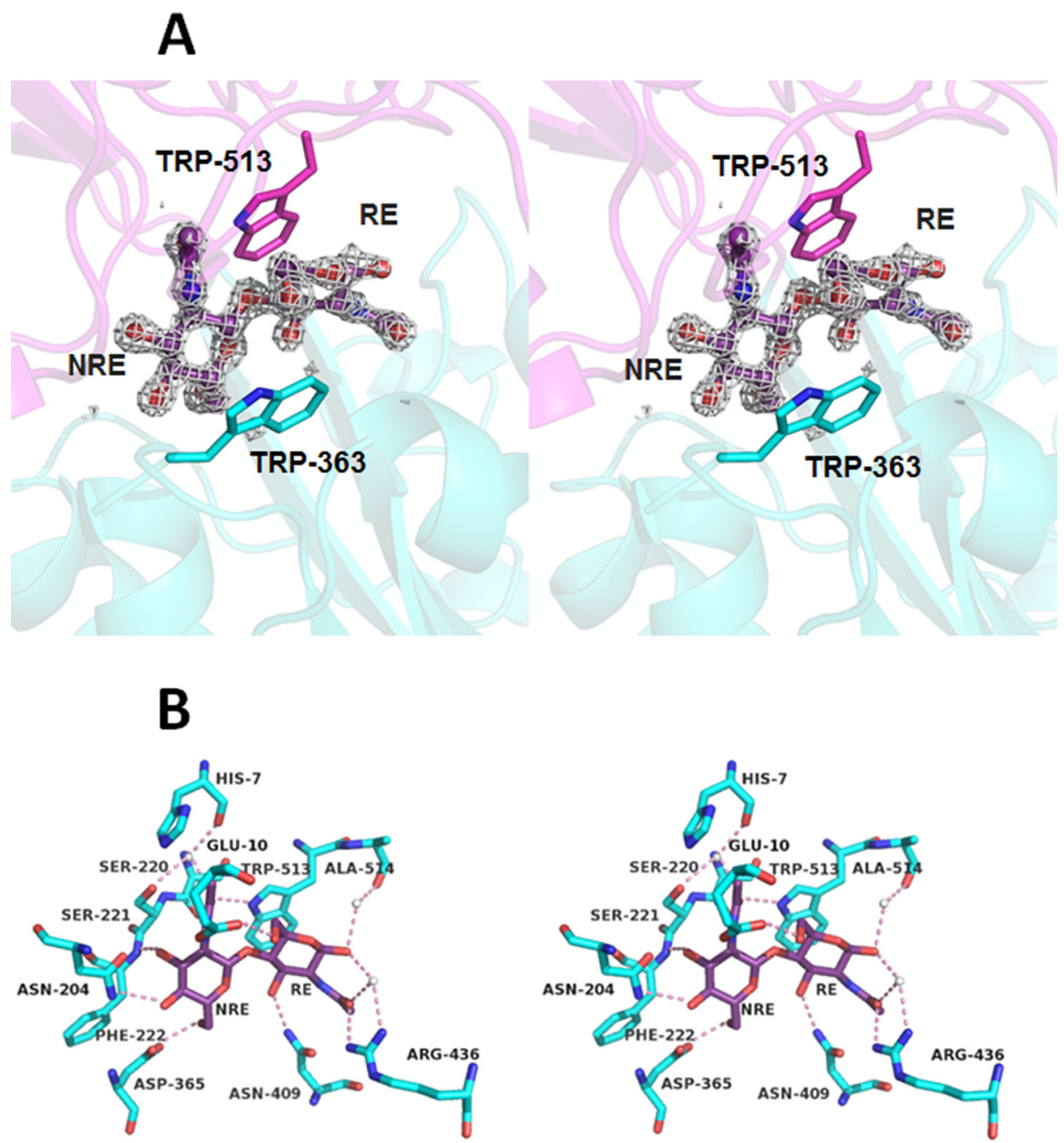

Figure 6. $A$, stereo representation of the close-up view of (GlcNAc) ${ }_{2}$ bound to $V h C B P$. The main chain structure of VhCBP is colored in magenta for the upper domain and in cyan for the lower domain. The bound $(\mathrm{GlcNAc})_{2}$ is represented by ball-and-stick model colored in wine red. The $2 F_{\mathrm{obs}}-F_{\mathrm{cal}}$ omit map for $(\mathrm{GlCNAc})_{2}$ is colored in gray and is contoured at $1 \sigma$. The Trp-363 side chain from the lower domain interacts with the non-reducing end GIcNAc, whereas the Trp-513 side chain from the upper domain interacts with the reducing end GlcNAc through $\mathrm{CH}-\pi$ stacking interactions. $B$, stereo view of the interactions between $\mathrm{VhCBP}$ and $(\mathrm{GlcNAC})_{2}$. The bound (GlcNAc) ${ }_{2}$ is shown as stick model colored in wine red, and the amino acid residues interacting with (GlcNAc) are shown as stick model colored in cyan. Water molecules are represented by white spheres. Hydrogen bonds are represented as dotted lines. NRE and RE represent the non-reducing end GlcNAc and the reducing end GlcNAc, respectively.

markedly different from that of $V h C B P$. The role of metal ion in the function of CBP is still unclear.

In the binding experiments of $V h C B P$, we tested only chitin and its oligosaccharides. In the complexed structure, both acetamido groups in bound (GlcNAc) ${ }_{2}$ are recognized by $V h C B P$ in addition to the hydroxyl groups of the pyranose rings (Fig. $6 B$ ). In the complexed structure, both acetamido groups in bound $(\mathrm{GlcNAc})_{2}$ made substantial interactions with polar residues in the sugar-binding pocket. These functional groups are predicted to play a crucial role in sugar specificity of $V h C B P$. The deacetylated oligosaccharides may interact, but weak interactions with $V h C B P$ are expected because of the lack of the crucial acetamido groups.

Bacterial chitooligosaccharide-binding proteins are part of the chitin degradation pathway. The proteins usually recognize homochitooligomers not branched sugars. Structural inspection of VhCBP suggested a small, narrow sugar-binding pocket, with both ends of the sugar-binding sites not open to accom- modate long-chain sugars or branched glycans. The feature of the sugar-binding pocket appears to determine the substrate specificity of this protein.

Conformational changes of periplasmic SBPs, such as ribosebinding protein, allose-binding protein, leucine/isoleucine/valine-binding protein, and leucine-binding protein, were intensively studied by X-ray crystallography (22-25). These SBPs adopt a similar fold made of two lobes, which are connected by one or more polypeptide chains, forming a hinge. Most SBP ligands were found to bind to this hinge region between the lobes. The binding of a ligand brings about a dramatic conformational change from opened form to closed form, and the ligand is then clamped between the two lobes. The structural findings for $V h C B P$ including the binding mechanism and the conformational change are consistent with those of perplasmic SBPs reported to date. Thus, these structural aspects appeared to be a general feature among the periplasmic SBPs. However, multiple conformations were found in opened structures of 
ribose- and allose-binding proteins $(23,24)$, suggesting that the conformational changes of these SBPs do not take place through a one-step transition from open to close conformation. In $V h C B P$, however, we failed to obtain the crystal structure of the open form. Further structural studies should be conducted to identify the mechanism of conformational change in CBPs from bacteria. Hollenstein et al. (26) reported that the SBPligand complex in closed form possesses a protein-binding surface not present in the open form, suggesting that ligand binding followed by the conformational change may be essential for SBP to be recognized by membrane-bound transporter protein. To further characterize our VhCBP protein, we are now trying to observe the interaction between $V h C B P$ and the transporter protein from $V$. harveyi, in addition to the structural studies.

\section{Experimental procedures}

\section{Materials}

Solid $\alpha$-chitin and $\beta$-chitin originated from crab and squid pen, respectively, were purchased from Marine BioResources Co. Ltd. (Samut Sakhon, Thailand), and their derivatives, colloidal chitins, were prepared by the method of Roberts and Selitrennikoff (27). Chitin oligosaccharides, (GlcNAc) ${ }_{n}(n=2-6)$, were purchased from Seikagaku Biobusiness Co. (Tokyo, Japan). E. coli strain Origami (DE3) cells and the expression vector pET23a $(+)$ were from GeneScript Co. (Piscataway, NJ). $\mathrm{Ni}^{2+}$-affinity resin, nickel-nitrilotriacetic acid, was also purchased from GeneScript Co. HiTrap Q and 16/60 Superdex 200 were from GE Healthcare (Chicago, IL). All other reagents were of analytic grade.

\section{Expression plasmid}

The pET23a $(+)$ plasmid containing a synthetic gene encoding VhCBP fused with the $\mathrm{His}_{6}$ tag at the $\mathrm{C}$ terminus was obtained from GeneScript Co. and designated as pET23a(+)$V h C B P$. The sequence of the $V h C B P$-encoding region was amplified by PCR and confirmed to contain the exactly correct sequence of $V h C B P$ from the restriction fragment profile.

\section{Protein expression and purification}

The expression plasmid, pET23a(+)-VhCBP, was transformed into $E$. coli strain Origami (DE3) cells, which were inoculated into $10 \mathrm{ml}$ of LB broth containing ampicillin/kanamycin and grown overnight at $30^{\circ} \mathrm{C}$, while shaking at $200 \mathrm{rpm}$. After centrifugation at $4,500 \mathrm{rpm}$ and $4{ }^{\circ} \mathrm{C}$ for $20 \mathrm{~min}$, the cells were harvested, resuspended in $10 \mathrm{ml}$ of LB broth containing ampicillin/kanamycin, and then transferred to 1 liter of LB broth containing ampicillin. The culture was incubated at $37^{\circ} \mathrm{C}$, shaking at $200 \mathrm{rpm}$, until optical density at $600 \mathrm{~nm}$ reached 0.7 . After cooling down the culture by sitting in ice-cold water for $20 \mathrm{~min}$, isopropyl $\beta$-D-1-thiogalactopyranoside was added to a final concentration of $0.5 \mathrm{~mm}$ to induce expression. The culture was allowed to incubate at $25^{\circ} \mathrm{C}$ for $16 \mathrm{~h}$ and then centrifuged at 4,500 rpm for $15 \mathrm{~min}$ to harvest the cells. The cells obtained were resuspended in $20 \mathrm{~mm}$ sodium phosphate, $\mathrm{pH}$ 7.4, containing $50 \mathrm{~mm} \mathrm{NaCl}, 1 \mathrm{~mm}$ phenylmethylsulfonyl fluoride, $10 \%$ glycerol, $0.1 \%$ Triton X-100, and 3 units of DNase and then sonicated for $10 \mathrm{~min}$. The cell debris was removed by centrifuge at $12,000 \mathrm{rpm}$ and $4{ }^{\circ} \mathrm{C}$ for $20 \mathrm{~min}$, and the supernatant was applied onto a nickel-nitrilotriacetic acid column $(2 \mathrm{ml}$ of recharged resin) equilibrated with $20 \mathrm{~mm}$ sodium phosphate buffer, $\mathrm{pH}$ 7.4, containing $50 \mathrm{~mm} \mathrm{NaCl}$ and $10 \mathrm{~mm}$ imidazole. After washing the column with $100 \mathrm{ml}$ of the equilibration buffer, the adsorbed protein was eluted with $30 \mathrm{ml}$ of the same buffer containing $150 \mathrm{~mm}$ imidazole. The eluted protein fractions were pooled and dialyzed against $20 \mathrm{~mm}$ sodium phosphate, $\mathrm{pH} 7.4$, containing $50 \mathrm{~mm} \mathrm{NaCl}$. The resultant protein solution was filtered with a $0.45-\mu \mathrm{m}$ membrane filter and applied onto a HiTrap Q column (5 ml) equilibrated with the dialysis buffer. After washing the column with the same buffer, the adsorbed proteins were eluted with a linear gradient elution from $50 \mathrm{~mm}$ to $0.5 \mathrm{M} \mathrm{NaCl}$ in the same buffer. The protein fractions were pooled and finally purified by a gel-filtration column of $16 / 60$ Superdex 200. After confirming a single protein band on SDS-PAGE (28) (Fig. 2A), the purified $V h C B P$ fractions were stored at $4{ }^{\circ} \mathrm{C}$ and used for subsequent experiments. Protein concentration was determined by reading absorbance at $280 \mathrm{~nm}$, using the extinction coefficients, $103,375 \mathrm{M}^{-1} \mathrm{~cm}^{-1}$, calculated from the equation proposed by Pace et al. (29).

\section{Chitin-binding assay}

Binding experiments using insoluble chitins (colloidal $\alpha$-chitin and colloidal $\beta$-chitin) were conducted at $4{ }^{\circ} \mathrm{C}$. A reaction mixture $(500 \mu \mathrm{l})$ comprising $5 \mu \mathrm{g}$ of $V h \mathrm{CBP}, 1.0 \mathrm{mg}$ of colloidal chitin, and $20 \mathrm{~mm}$ Tris-HCl buffer, $\mathrm{pH}$ 8.0, containing $150 \mathrm{~mm}$ $\mathrm{NaCl}$ was incubated for $30 \mathrm{~min}$ and then centrifuged at 12,000 rpm and $4{ }^{\circ} \mathrm{C}$ for $10 \mathrm{~min}$. The supernatant $(100 \mu \mathrm{l})$ was mixed with the Coomassie Brilliant Blue G-250 dye solution, and the protein concentration was determined by the method of Bradford (30). The amount of bound protein was calculated by subtracting the free protein content at the equilibrium from the initial protein content and then converted to the bound protein fraction (\%). VhChiA, a chitinase A from $V$. harveyi, was used as a positive control of these experiments, because the enzyme protein was reported to have a high affinity toward the insoluble chitin (18).

\section{ITC experiments}

The $V h C B P$ solution $(80-90 \mu \mathrm{M})$ in $20 \mathrm{~mm}$ potassium phosphate buffer ( $\mathrm{pH}$ 8.0) was degassed, and its concentration was determined. Individual (GlcNAc) ${ }_{n}$ (where $n=1,2,3,4,5$, and 6) $(0.1 \mathrm{~mm})$ were dissolved in the same buffer, and the solution $\mathrm{pH}$ was adjusted to 8.0. Then the (GlcNAc) ${ }_{n}$ solution was degassed and loaded into a syringe, whereas the protein solution $(0.2028 \mathrm{ml})$ was loaded into the sample cell after confirming the solution $\mathrm{pH}$ 8.0. Calorimetric titration was performed with an iTC200 system (Microcal, Northampton, MA) at $4{ }^{\circ} \mathrm{C}$. Aliquots $(1.0-2.0 \mu \mathrm{l})$ of the ligand solution were added to the sample cell with a stirring speed of $1000 \mathrm{rpm}$. Titrations were completed after 40 injections. For analysis of the ITC data, the Origin software installed in an ITC instrument was used. The one-set-of-sites model was employed to fit the experimental data. The other details of the data analysis were previously described (21). 


\section{Crystallization and data collection}

Crystal trials were set up by the sitting-drop, vapor-diffusion method with Morpheus and structure screen kits (Molecular Dimensions Limited, Suffolk, UK) using a Mosquito robot (TTB Labtech). Crystals plated were incubated at $20^{\circ} \mathrm{C}$, and small crystals grown were observed under several conditions within 3 days of incubations. Further optimization was carried out manually using the hanging-drop, vapor-diffusion method. $1 \mu \mathrm{l}$ aliquot of the protein solution $(10-15 \mathrm{mg} / \mathrm{ml}$ in $10 \mathrm{~mm}$ HEPES, pH 7.5, $150 \mathrm{~mm} \mathrm{NaCl)} \mathrm{was} \mathrm{mixed} \mathrm{with} 1.5 \mu \mathrm{l}$ of a reservoir solution. Bipyramidal crystals were observed with Morpheus conditions B4 (0.09 M Halogens (NaF, NaBr, NaI), $0.1 \mathrm{M}$ buffer 2 (HEPES/MOPS), pH 7.5, and 37.5\% MPD_P1K_P3350 mix). The crystals were collected, briefly transferred to a solution of mother liquor containing 20\% PEG400, and then flashfrozen in liquid nitrogen. One of the crystals diffracted at the highest resolution of $1.36 \AA$, and the structure was solved in PHENIX (31) using 1ZU0 as a molecular replacement model. For data collection under cryogenic conditions, the crystals were briefly transferred to the mother liquor and were then flash-cooled by a nitrogen stream at $95 \mathrm{~K}$. The data set of the crystals was collected at $95 \mathrm{~K}$ at the Beamline I04-1 (Diamond Light Source, Didkot, UK). The resulting data set was processed with Dials and scaled with Aimless (32) in PHENIX. The crystals belong to the triclinic space group $P 3_{1} 2_{1}$, with unit cell dimensions of $a=54.68 \AA, b=54.68 \AA, c=306.45 \AA, \alpha=90.0^{\circ}$, $\beta=90.0^{\circ}$, and $\gamma=120.0^{\circ}$. The processing statistics are summarized in Table 2 .

\section{Structure determination and refinement}

Initial phasing and modeling was done using AUTOSOL within PHENIX (31). Further model building was performed using the program COOT (33). The phase for VhCBP was obtained by molecular replacement using MOLREP (34) with the structure of $V c C B P$ in complex with (GlcNAc) (PDB code $^{2}$ 1ZU0) as the search model. The analyses of the electron density map $F_{\text {obs }}-F_{\text {cal }}$ and $2 F_{\text {obs }}-F_{\text {cal }}$ and model building were carried out in COOT and restrained refinement in REFMAC5 (35). The geometry of the final model was validated by MolProbity (36). The final $2 F_{\text {obs }}-F_{\text {cal }}$ omit map, contoured at $3.0 \sigma$, clearly showed the electron density map for (GlcNAc) $)_{2}$ with full occupancy. The structures and electron density maps of all the refined structures were created and displayed by PyMOL (37). The refinement statistics are summarized in Table 2.

Author contributions-W. S. and T. F. conceptualization; W. S. resources; W. S., A. R., D. B., and B. v. d. B. data curation; W. S. and B. v. d. B. formal analysis; W. S., B.v. d. B., and T. F. supervision; W. S. funding acquisition; W. S., A. R., D. B., B. v. d. B., and T. F. validation; W. S., N. S., A. R., D. B., and Y. K. investigation; W. S., N. S., A. R., and T. F. visualization; W. S., N. S., A. R., D. B., Y. K., and B. v. d. B. methodology; W. S. and T. F. project administration; W. S. and B. v. d. B. writing-review and editing; T. F. writing-original draft.

Acknowledgment-We gratefully acknowledge the Centre for Scientific and Technological Equipment, Suranaree University of Technology for providing the facilities for carrying out this research.
Note added in proof-Fig. 3, $A$ and $F$, was inadvertently duplicated in the version of this article that was published as a Paper in Press on February 14, 2018. This error has now been corrected and does not affect the results or conclusions of this work.

\section{References}

1. Austin, B., and Zhang, X. H. (2006) Vibrio harveyi: a significant pathogen of marine vertebrates and invertebrates. Lett. Appl. Microbiol. 43, 119-124 CrossRef Medline

2. Songsiriritthigul, C., Pantoom, S., Aguda, A. H., Robinson, R. C., and Suginta, W. (2008) Crystal structures of Vibrio harveyi chitinase A complexed with chitooligosaccharides: implications for the catalytic mechanism. J. Struct. Biol. 162, 491-499 CrossRef Medline

3. Suginta, W., Pantoom, S., and Prinz, H. (2009) Substrate binding modes and anomer selectivity of chitinase A from Vibrio harveyi.J. Chem. Biol. 2, 191-202 CrossRef Medline

4. Sritho, N., and Suginta, W. (2012) Role of Tyr-435 of Vibrio harveyi chitinase A in chitin utilization. Appl. Biochem. Biotechnol. 166, 1192-1202 CrossRef Medline

5. Suginta, W., and Sritho, N. (2012) Multiple roles of Asp313 in the refined catalytic cycle of chitin degradation by Vibrio harveyi chitinase A. Biosci. Biotechnol. Biochem. 76, 2275-2281 CrossRef Medline

6. Meekrathok, P., Bürger, M., Porfetye, A. T., Vetter, I. R., and Suginta, W. (2015) Expression, purification, crystallization and preliminary crystallographic analysis of a GH20 $\beta$ - $N$-acetylglucosaminidase from the marine bacterium Vibrio harveyi. Acta Crystallogr F Struct. Biol. Commun. 71, 427-433 CrossRef Medline

7. Meekrathok, P., and Suginta, W. (2016) Probing the catalytic mechanism of Vibrio harveyi GH2O $\beta$ - $N$-acetylglucosaminidase by chemical rescue. PLoS One 11, e0149228 CrossRef Medline

8. Kadokura, K., Rokutani, A., Yamamoto, M., Ikegami, T., Sugita, H., Itoi, S., Hakamata, W., Oku, T., and Nishio, T. (2007) Purification and characterization of Vibrio parahaemolyticus extracellular chitinase and chitin oligosaccharide deacetylase involved in the production of heterodisaccharide from chitin. Appl. Microbiol. Biotechnol. 75, 357-365 CrossRef Medline

9. Li, X., Wang, L. X., Wang, X., and Roseman, S. (2007) The chitin catabolic cascade in the marine bacterium Vibrio cholerae: characterization of a unique chitin oligosaccharide deacetylase. Glycobiology 17, 1377-1387 CrossRef Medline

10. Hirano, T., Kadokura, K., Ikegami, T., Shigeta, Y., Kumaki, Y., Hakamata, W., Oku, T., and Nishio, T. (2009) Heterodisaccharide 4-O-( $N$-acetyl- $\beta$ D-glucosaminyl)-D-glucosamine is a specific inducer of chitinolytic enzyme production in Vibrios harboring chitin oligosaccharide deacetylase genes. Glycobiology. 19, 1046-1053 CrossRef Medline

11. Li, X., and Roseman, S. (2004) The chitinolytic cascade in Vibrios is regulated by chitin oligosaccharides and a two-component chitin catabolic sensor/kinase. Proc. Natl. Acad. Sci. U.S.A. 101, 627-631 CrossRef Medline

12. Suginta, W., Chumjan, W., Mahendran, K. R., Janning, P., Schulte, A., and Winterhalter, M. (2013) Molecular uptake of chitooligosaccharides through chitoporin from the marine bacterium Vibrio harveyi. PLoS One 8, e55126 CrossRef Medline

13. Suginta, W., Chumjan, W., Mahendran, K. R., Schulte, A., and Winterhalter, M. (2013) Chitoporin from Vibrio harveyi, a channel with exceptional sugar specificity. J. Biol. Chem. 288, 11038-11046 CrossRef Medline

14. Chumjan, W., Winterhalter, M., Schulte, A., Benz, R., and Suginta, W. (2015) Chitoporin from the marine bacterium Vibrio harveyi: Probing the essential roles of $\operatorname{Trp}^{136}$ at the surface of the constriction zone. J. Biol. Chem. 290, 19184-19196 CrossRef Medline

15. Davidson, A. L., Dassa, E., Orelle, C., and Chen, J. (2008) Structure, function, and evolution of bacterial ATP-binding cassete systems. Microbiol. Mol. Biol. Rev. 72, 317-364. CrossRef Medline

16. Cockerell, S. R., Rutkovsky, A. C., Zayner, J. P., Cooper, R. E., Porter, L. R., Pendergraft, S. S., Parker, Z. M., McGinnis, M. W., and Karatan, E. (2014) Vibrio cholerae NspS, a homologue of ABC-type periplasmic solute bind- 


\section{Chitooligosaccharide-binding protein from Vibrios}

ing proteins, facilitates transduction of polyamine signals independent of their transport. Microbiology 160, 832-843 CrossRef Medline

17. Hall, J. A., Ganesan, A. K., Chen, J., and Nikaido, H. (1997) Two modes of ligand binding in maltose-binding protein of Escherichia coli: functional significance in active transport. J. Biol. Chem. 272, 17615-17622 CrossRef Medline

18. Suginta, W., Sirimontree, P., Sritho, N., Ohnuma, T., and Fukamizo, T. (2016) The chitin-binding domain of a GH-18 chitinase from Vibrio harveyi is crucial for chitin-chitinase interactions. Int. J. Biol. Macromol. 93, 1111-1117 CrossRef Medline

19. Tam, R., and Saier, M. H. (1993) Structural, functional, and evolutionary relationships among extracellular solute-binding receptors of bacteria. Microbiol. Rev. 57, 320-346 Medline

20. Hamre, A. G., Jana, S., Holen, M. M., Mathiesen, G., Väljamäe, P., Payne, C. M., and Sørlie, M. (2015) Thermodynamic relationships with processivity in Serratia marcescens family 18 chitinases. J. Phys. Chem. B 119, 9601-9613 CrossRef Medline

21. Ohnuma, T., Sørlie, M., Fukuda, T., Kawamoto, N., Taira, T., and Fukamizo, T. (2011) Chitin oligosaccharide binding to a family GH19 chitinase from the moss Bryum coronatum. FEBS J. 278, 3991-4001 CrossRef Medline

22. Shilton, B. H., Flocco, M. M., Nilsson, M., and Mowbray, S. L. (1996) Conformational changes of three periplasmic receptors for bacterial chemotaxis and transport: the maltose-, glucose/galactose-and ribose-binding proteins. J. Mol. Biol. 264, 350-363 CrossRef Medline

23. Björkman, A. J., and Mowbray, S. L. (1998) Multiple open forms of ribosebinding protein trace the path of its conformational change. J. Mol. Biol. 279, 651-664 CrossRef Medline

24. Magnusson, U., Chaudhuri, B. N., Ko, J., Park, C., Jones, T. A., and Mowbray, S. L. (2002) Hinge-bending motion of D-allose-binding protein from Escherichia coli: three open conformations. J. Biol. Chem. 277, 14077-14084 CrossRef Medline

25. Magnusson, U., Salopek-Sondi, B., Luck, L. A., and Mowbray, S. L. (2004) $\mathrm{X}$-ray structures of the leucine-binding protein illustrate conformational changes and the basis of ligand specificity. J. Biol. Chem. 279, 8747-8752 CrossRef Medline

26. Hollenstein, K., Frei, D. C., and Locher, K. P. (2007) Structure of an ABC transporter in complex with its binding protein. Nature 446, 213-216 CrossRef Medline
27. Roberts, W. K., and Selitrennikoff, C. P. (1988) Plant and bacterial chitinases differ in antifungal activity. J. Gen. Microbiol. 134, 169-176

28. Laemmli, U. K. (1970) Cleavage of structural proteins during the assembly of the head of bacteriophage T4. Nature 227, 680-685 CrossRef Medline

29. Pace, C. N., Vajdos, F., Fee, L., Grimsley, G., and Gray, T. (1995) How to measure and predict the molar absorption coefficient of a protein. Protein Sci. 4, 2411-2423 CrossRef Medline

30. Bradford, M. M. (1976) A rapid and sensitive method for the quantitation of microgram quantities of protein utilizing the principle of protein-dye binding. Anal. Biochem. 72, 248-254 CrossRef Medline

31. Adams, P. D., Afonine, P. V., Bunkóczi, G., Chen, V. B., Davis, I. W., Echols, N., Headd, J. J., Hung, L. W., Kapral, G. J., Grosse-Kunstleve, R. W., McCoy, A. J., Moriarty, N. W., Oeffner, R., Read, R. J., Richardson, D. C., et al. (2010) PHENIX: a comprehensive Python-based system for macromolecular structure solution. Acta Crystallogr. D Biol. Crystallogr. 66, 213-221 CrossRef Medline

32. Evans, P. R., and Murshudov, G. N. (2013) How good are my data and what is the resolution? Acta Crystallogr. D Biol. Crystallogr. 69, 1204-1214 CrossRef Medline

33. Emsley, P., and Cowtan, K. (2004) Coot: model-building tools for molecular graphics. Acta Crystallogr. D Biol. Crystallogr. 60, 2126-2132 CrossRef Medline

34. Vagin, A., and Teplyakov, A. (1997) MOLREP: an automated program for molecular replacement. J. Appl. Crystallogr. 30, 1022-1025 CrossRef

35. Murshudov, G. N., Skubák, P., Lebedev, A. A., Pannu, N. S., Steiner, R. A., Nicholls, R. A., Winn, M. D., Long, F., and Vagin, A. A. (2011) REFMAC5 for the refinement of macromolecular crystal structures. Acta Crystallogr. D Biol. Crystallogr. 67, 355-367 CrossRef Medline

36. Chen, V. B., Arendall, W. B., 3rd, Headd, J. J., Keedy, D. A., Immormino, R. M., Kapral, G. J., Murray, L. W., Richardson, J. S., and Richardson, D. C. (2010) MolProbity: all-atom structure validation for macromolecular crystallography. Acta Crystallogr. D Biol. Crystallogr. 66, 12-21 CrossRef Medline

37. DeLano, W. L. ( 2012) The PyMOL Molecular Graphics System, version 1.5.0.1, Schroedinger, LLC, New York

38. Lombard, V., Golaconda Ramulu, H., Drula, E., Coutinho, P. M., and Henrissat, B. (2014) The carbohydrate-active enzymes database (CAZy) in 2013. Nucleic Acids Res. 42, D490-D495 